\title{
Evaluation of deciduous broadleaf forests mountain using satellite data using neural network method near Caspian Sea in North of Iran
}

\author{
SEYED A. HASHEMI \\ Department of Forestry, Lahijan Branch, Islamic Azad University, 1616, Lahijan, Iran \\ Manuscript received on August 26, 2015; accepted for publication on October 20, 2015
}

\begin{abstract}
During the recent decades, deciduous forests have been molested by human intervention. Easy access, abundance and diversity of valuable forest products have led to increased population density, creating new residential areas and deforestation activities. Revealing changes is one of the fundamental methods in management and assessment of natural resources. This study is evaluated changes in forests area of 2013 using satellite images. In order to mapping the forest extent condition 2013, images of the mentioned years were digitized and geo-referenced by using the ground control points and the maps of mapping organization. After selecting the best set of band using the Bhattacharya distance index, the image classification was performed by using artificial neural network algorithm. Classification by neural network method 2013 in showed that it has a high overall accuracy equal to $95.96 \%$.
\end{abstract}

Key words: satellite data, ETM+, forest area, classification.

\section{INTRODUCTION}

The present study will be done to determine land use level change of Siah Mazgi basin forests of shaft city and explain the factors influencing these changes using remote sensing and GIS. Based on this, Landsat satellite images of 2000 and 2013 will be used. Research methodology will be done using neural network classification method. Neural networks method is considered as a proper method for classification of land use and land cover, because it can be used for all kinds of data in various statistical scales (Chavez 1988). One of the most important features of neural network is its independence to statistical distribution of the input data. This important feature of neural networks

E-mail: sahashemi1980@yahoo.com that enables them to combine the information with different distributions, is their special superiority compared to statistical methods. Neural networks, with their remarkable ability to derive conclusions from complex data, can successfully extract patterns and detect various trends which are very difficult to identify for human and computer. Of other advantages of neural networks, which make them suitable for development of predictive models can be mentioned to adaptive learning, being self-organizing, fault tolerance, generalization, sustainability and flexibility of these networks (Dellepiane and Smith 1999, Hilbert and Ostendorf 2001). The artificial neural network and maximum likelihood classification algorithm for mapping dry land regional lands in the southeastern. The results showed that neural network classification 
method including texture features is more accurate than maximum algorithm. The comparison of classification in artificial and fuzzy neural networks technique has been conducted to separate classes of forest from non-forest using SPOT satellite neural network method with the accuracy of $64 \%$ and kappa coefficient of 0.4 has higher accuracy than fuzzy method with the accuracy of $36 \%$ and Kappa coefficient of 0.20. Murayama and Khoi in an area at North Vietnam in 2011, modeled the destruction of forests using artificial neural network and Markov chain models (Montserud and Leamans 1992, Khoi and Murayama 2011). This study showed that the degradation in the boundary between forests and agricultural lands, areas close to water sources and areas with lower altitude is more intense. Neural network and GIS were used to assess the potential of climate changes effects on a complex landscape of northeastern Queensland tropical forests. Model inputs included variables of climate, soil parent material classes and ground variables. The obtained model was very successful in detecting forest classes with $75 \%$ accuracy of prediction. Changes in vegetation have been modeled in Australia using two logistic regression and artificial neural networks approach (Pijanowski et al. 2001). The results showed that both methods are capable of modeling vegetation changes, however neural network has a relatively better performance (Ahamed et al. 2011). The purpose of this study Evaluation of forests mountain use satellite data ETM+ with neural Network method in near Caspian

\section{SELECTING THE USED IMAGES}

The images used in this study are of the Landsat 8 satellite images 2013. The mission of this satellite, like the previous satellites of Landsat family, is to obtain the required data from the ground to monitor natural resources and remote sensing affairs. Landsat 8 satellite was launched on 11 February 2013. This is the eighth satellite in the
Landsat satellites program, and the seventh satellite which has successfully reached to the orbit. This satellite which is originally called Continuity Mission (LDCM) Landsat Data, is a product of collaboration between NASA and United States Geological Survey (USGS).

\section{IMAGES PREPROCESSING}

\section{Geometric correction}

In this study, for geometric correction operations of images, the extraction of drainages and roads network from 1:25,000 maps of mapping organization and adapting them with received images from the Rice Research Institute of Gilan province was carried out. Then, the control points were randomly taken from all over the area. Since the image from the rice Institute is geo-referenced, very little geometric errors were observed in the pixels. Due to the appropriate resolution of Landsat satellite PAN band $(15 \mathrm{~m})$, first, the image of this band was corrected compared to $1: 25,000$ maps and then, other bands of 2013 image. It should be mentioned that the total RMSE error was equal to 0.4 for images of 2013. The more differences in spectral reflectance between bands, the higher accuracy the separation of effects and phenomena will be possible. The best band combination in this survey was selected the combination 367 for $\mathrm{ETM}^{+}$ images of 2013 (Figure 1).

\section{Image Classification}

The classification method selected in this study is the neural network method. The concept of artificial neural network is taken from the human nervous system. In such networks, a set of processor elements similar to the human nervous neurons is located next to each other in a topological structure to perform information processing operations in parallel. Characteristics of artificial neural network can be named as Learning ability, generalization, information Parallel Processing. Artificial neural 


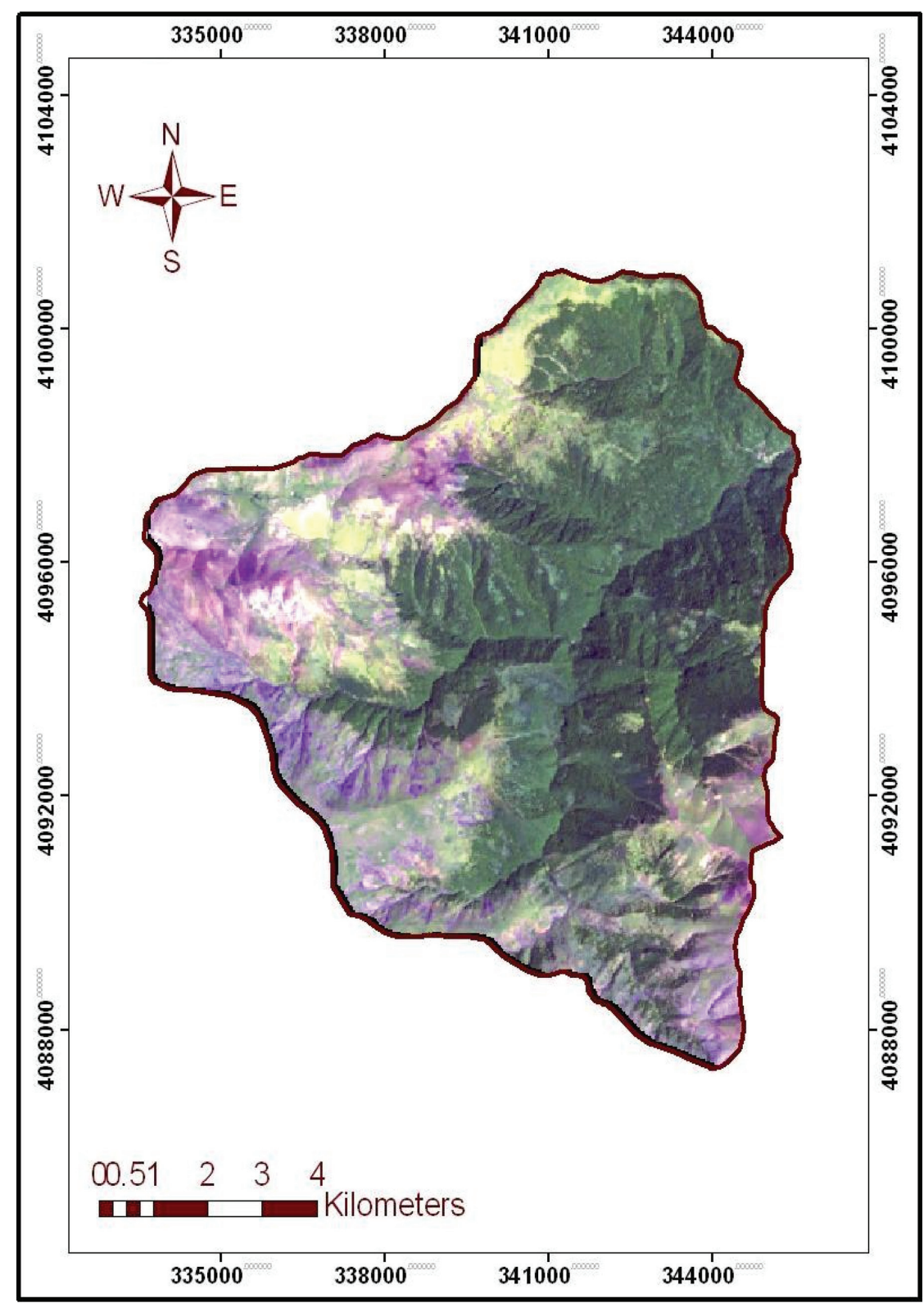

Figure 1 - Band combination 3, 6, 7 in the image of 2013.

network is either supervised or unsupervised. In supervised network, the input is applied to system and difference between the network output and the optimum output is used to change and adapt the weights. While in unsupervised network, the network adjusts itself proportional to the input data. The network response is due to learning algorithm and input data. In recent years, the use of artificial neural networks has been developed for various applications. One of the best applications is their use for classification of multispectral remote sensing images. One of the most important features of artificial neural networks is not being dependent to the initial assumptions about the input data, that is, the input data can have any arbitrary statistical distribution. This important feature of neural networks is their specific advantage in front of statistical methods, which gives them the ability to use different types of input data equally with any arbitrary distribution (Stehman 2004). Also, having 


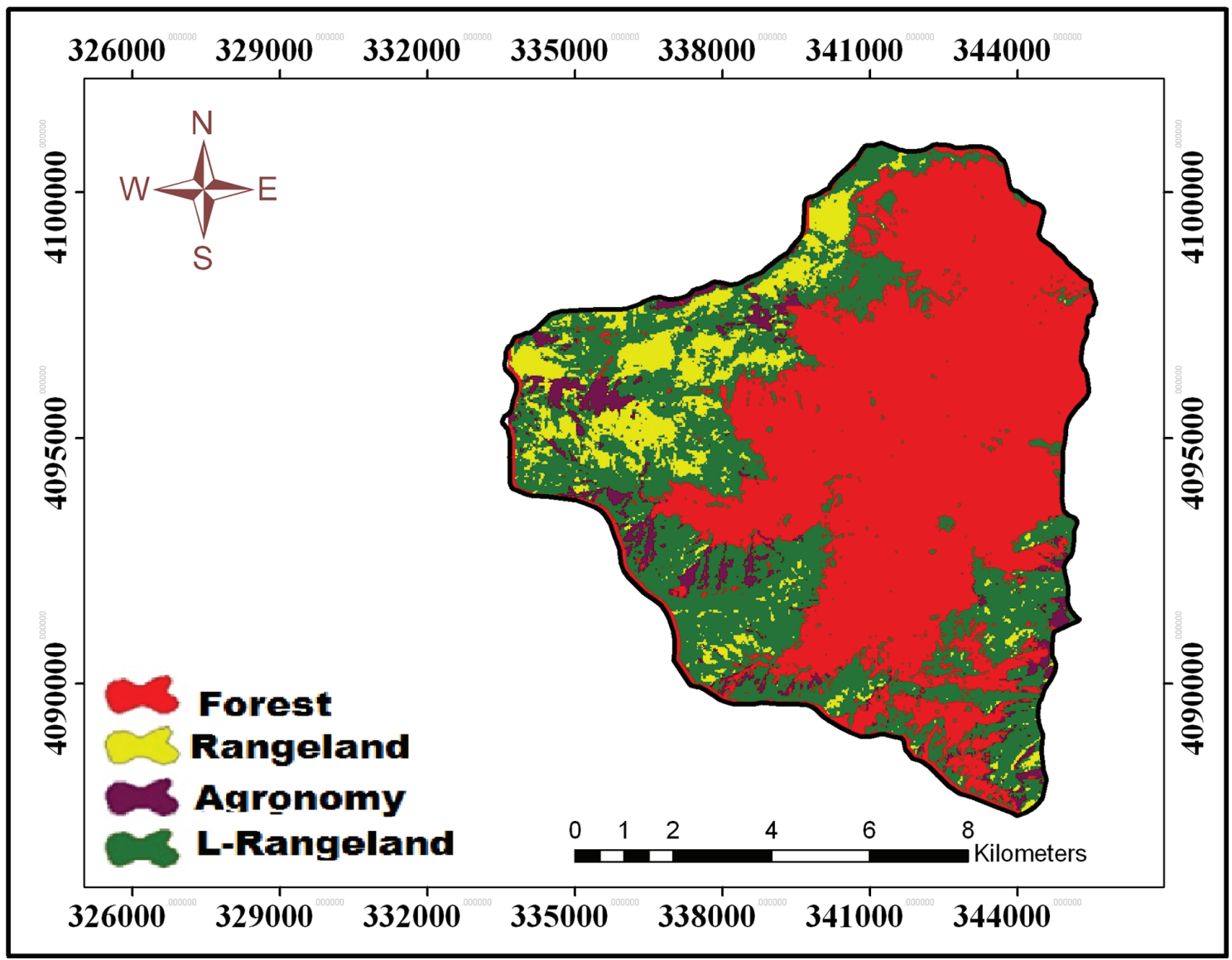

Figure 2 - Land uses map of 2013 with maximum likelihood classification method.

many other features such as high processing speed (due to parallel processing), having potential to solve the problems which their simulation through logical or other methods are difficult or impossible, the network being efficient to learn and adapt with environment in case of changing the environmental conditions, lack of network breakdown in case of damage to a part of the neurons and having logical answer for data in confidence terms (whether they are fuzzy or are received incompletely and coupled with receiving noise), increases the interest in using this method.

\section{RESULTS}

In this study, the two methods of overall accuracy and kappa coefficient were used for evaluation of produced layers. In fact, half of the ground facts data which were obtained from different areas in the field operation by GPS or from visual interpretation and by the use of high-resolution images and available maps, were used in classification training phase and the other half of the data were used in monitoring and evaluation phase of classification accuracy. The reason of this method in the use of ground facts is to prevent optimistically assessment results. The diagonal of variance-covariance matrix includes the number of correctly classified pixels and the elements out of the matrix in rows represent the correctly unclassified pixels which during the classification have been logged by mistake from the main class and assigned to other classes. These errors are also called the Errors of Omission or Exclusion. Kappa coefficient and overall accuracy of $\mathrm{ETM}^{+}$image of 2013 is shown in Table I. 
Distribution of land use levels separately for years 2013 shown in Figure 2 and table II. The maximum of class land type in forest type is 5575.17 hectares.

TABLE I

Kappa coefficient and overall accuracy of Landsat 8, image of 2013.

\begin{tabular}{cc}
\hline Kappa coefficient (percent) & Overall accuracy \\
\hline 0.9007 & 0.9596 \\
\hline
\end{tabular}

TABLE II

Distribution of land use levels separately for year 2013.

\begin{tabular}{ccc}
\hline \multirow{2}{*}{ Class of Lands } & \multicolumn{2}{c}{ Image of 2013 } \\
\cline { 2 - 3 } & Area (Hectare) & Area (\%) \\
\hline Forest & 5575.17 & 54.5 \\
\hline Agronomy & 448.40 & 32.5 \\
\hline Rangeland & 879.93 & 8.6 \\
\hline Semi-Rangeland & 2327.5 & 4.38 \\
\hline & 10228.8 & 100 \\
\cline { 2 - 3 }
\end{tabular}

\section{DISCUSSION}

Remote sensing and Geographic Information Systems techniques are the superior and efficient technologies in detecting environmental changes and resource management which provides updated information for management purposes (Darvish Sefat and Ein Allah 2008). Having timeliness information and statistics is essential for the proper management of natural realms. One of the principles of natural resource management is the information about land use change maps (Hashemi and Fallah Chai 2013). According to the high cost and lack of timeliness in preparation of these maps by ground operations, in recent years, the use of satellite images has been proposed as a method for doing this work. Overall accuracy of image classification in Landsat 8 image of 2013, were estimated at 0.9596 and 0.9007 , respectively, citing and comparing with sources (Table II, Figure 2). The results obtained from land uses classification using the satellite images in Siah Mazgi basin, both in terms of every single land uses and in terms of overall accuracy and Kappa statistic, have a good accuracy concerning the produced information. Also the results showed, a substantial portion of the pasture area has the forest origin and its natural land use changing and diverse uses of these lands has led it to convert to other land uses.

\section{CONCLUSIONS}

Also, the results showed, a substantial portion of the pasture area has the forest origin and its natural land use changing and diverse uses of these lands have led it to convert to other land uses. One of the basic of natural resources managements is the information's related to the land use changes maps. Taken the great cost required and not updating of map drawing by land operation, in recent years, using satellite images is considered as a technique for this purpose.

\section{REFERENCES}

AHAMED T, TIAN L, ZHANG Y AND TING KC. 2011. A review of remote sensing methods for biomass feedstock production. Biomass Bioenerg 35: 2455-2469.

CHAVEZ PS. 1988. An Improved Dark-Object Subtraction Technique for Atmospheric Scattering Correction of Multispectral Data. Remote Sens Environ 24: 459-479.

DARVISH SEFAT A AND EIN ALLAH F. 2008. Forest mapping with the help of Landsat TM data by digital method in lowland forests of Nour city. Iran J Nat Res 5: 244-249.

DELLEPIANE SG AND SMITH PC. 1999. Quality assessment of image classification algorithms for land cover mapping: A review and a proposal for a cost based approach. Int $\mathrm{J}$ Remote Sens 20: 1461-1486.

HASHEMI SA AND FALLAH CHAI M. 2013. Investigation of NDVI in relation to the growth phases of beech leaves in forest. Arab J Geosci 6(9): 3341-3347.

HILBERT DW AND OSTENDORF B. 2001. The utility of artificial neural networks for modeling the distribution of vegetation in past, present and future climates. Ecol Model 146: 311-327.

KHOI D AND MURAYAMA Y. 2011. Modeling deforestation using a neural network-Koi Markov model. In Murayama Y and Thapa RB (Eds), Spatial analysis and modeling in geographical transformation process: GIS-based applications, p.169-190, Dordrecht: Springer. 
MONTSERUD RA AND LEAMANS R. 1992. Comparing global vegetation maps with the kappa statistic. Ecol Model 62: 275-293.

PIJANOWSKI BC, BROWN DG, SHELLITO BA AND MANIK GA. 2001. Using neural networks and GIS to forecast land use changes: a Land Transformation Model. Comput Environ Urban 26(6): 553-575.

STEHMAN SV. 2004. A critical evaluation of the normalized error matrix in map accuracy assessment. Photogramm Eng Rem S 70: 743-751. 